ISSN : 2354 - 6034 (Print)

ISSN : 2599 - 0187 (Online)

\title{
PENGUPAHAN DALAM EKONOMI ISLAM TELAAH TAFSIR KONTENPORER AL-MISHBAH
}

\author{
Oleh: \\ IinMuyasarah \\ Magister EkonomiSyariah \\ Email: imuyasarah@gmail.com \\ Phone: +6282255781582
}

\begin{abstract}
Abstrak
Artikel ini mendiskripsikan tentang pengupahan dalam ekonomi Islam yang didasarkan oleh tafsir kontenporer al-mishbah. Kajian ini membahas tentang pengupahan, disebebkan oleh banyak sekali terjadi di masyakat pengupahan-pengupan yang tidak sesuai atau tidak mampu memenuhi kehidupan pekerjanya. Mengunakan metode penelitian kualitatif dengan pendekatan hermeneutika double movementsehingga diperoleh hasil yaitu, Standar upah minimum dalam Islam harus memenuhi dua syarat yaitu syarat adil dan layak dimana upah yang diterima seorang pekerja harus dapat mencukupi kebutuhan pokok pekerja dan keluarganya. Dan jika upah yang diterima tidak mencukupi kebutuhannya, maka Islam sendiri mengkatagorikan pekerja dalam ashanaf yang berhak menerima zakat.
\end{abstract}

Kata kunci: Upah, Ekonomi Islam, dan Tafsir Kontenporer

\section{A. Pendahuluan}

Pengupahan dalam Islam ialah memberikan hak pemanfaatan dengan syarat adanya imbalan. Perhitungan atau pertimbangan dasar penyusunan upah dan gaji antara lain upah menurut prestasi kerja, upah menurut lama kerja, upah menurut sinioritas, dan upah menurut kebutuhan. ${ }^{1}$

Upah berdasarkan perhitungan atau pertimbangan di atas hanya segelintir masyakarat yang dapat menikmati hal tersebut, karena fakta yang terjadi dilapangan masih banyak pekerja yang memperoleh upah tidak sesuai dengan mestinya sehingga berpengaruh terhadap kesejahtraan keluarganya. Berkembangnya zaman dan era saat ini lebih baik dari pada upah yang diterima oleh masyarakat di tahun sebelum, data yang didapat dari CNN indonesia tentang 5 Provinsi dengan UMP 2019 tertinggi dan terendah

${ }^{1}$ Siswadi, Pemberian Upah Yang Benar Dalam Islam Upaya Pemerataan Ekonomi Umat dan Keadilan, Jurnal Ummul Qura Vol IV, No. 2, Agustus 2014, h. 105. 
mengalami peningkatan 8 persen sampai 10,3 persen dari tahun sebelumnya. ${ }^{2}$ Adanya uu tentang upah minumum dan walaupun penetapan upah minimum sudah diatur oleh pemerintah dengan sedemikian rupa. Tetapi pada fakta di lapangan masih banyak upah-upah yang diterima pekerja tidak sesuai dengan mestinya atau tidak sesuai dengan upah minimum rakyat.

Pengupahan yang diterapkan dibeberapa perusahaan pada waktu tertentu seperti upah yang diterima di akhir bulan atau tiga bulan sekali, gaji yang tidak sesuai, seperti guru honorer yang digaji 700 ribu perbulan dan pemberian gajinya terjadi tiga bulan sekali, tentu saja hal tersebut tidak bisa memenuhi sandang pangan dan papan. Sedangkan dalam tafsir kontenporer almishbah yang membahas tentang pemberian upah yaitu harus mencakup keadilan dan kelayakan. Cakupan tentang upah sesuai dengan tarsir kontenporer al-mishbah bahwa keadilan yang diberikan dalam memberikan upah harus sesuai dengan kinerja yang dilakukan pekerjanya seperti jika kinerja karyawan tinggi sehingga menaikkan profit prusahaan maka wajib memberikan hadiah dari hasil kerjanya. Sedangkan kelayakan yang dimaksud yaitu upah yang diperoleh harus mampu mencukupi sandang, pangan, dan papan.

\section{B. Metode}

Metode penelitian dalam peper ini mengunakan jenis penelitian pustaka atau jenis penelitian kualitatif. Metode pendekatan yang digunakan dalam penulisan peper ini mengunakan pendekatan tafsir atau hermeneutika double movement. Teknik pengumpulan data mengunakan telaah pustaka dengan cara mengumpulkan ayat-ayat dan tafsir yang berkaitan tentang pengupahan yang telah di atur oleh Islam dalam Al-Qur'an. Selain mengunakan telaah pustaka berupa teks ayat Al-Qur'an dan tafsir yang berkaitan dengan pengupahan, di perlukan juga teknik telaah literatur berupa buku dan jurnal tentang pengupahan. Teknik analisis data dalam peper ini mengunakan teknik analisis isi tafsir.

\section{Result}

\section{Pengupahan dalam Islam}

Upah dalam Islam disebut dengan ujarah yang dihasilkan dari akad ijarah. Menurut ulama' Hanafiyah (ijarah)adalah transaksi terhadap suatu manfaat dengan imbalan tertentu yang dibolehkan. Jadi, upah (ujarah) adalah bentuk kompensasi atas jasa yang telah diberikan oleh tenaga kerja. ${ }^{3}$

Muamalah dalam Islam mengharuskan adanya kejelasan dalam segala bentuk transaksi (akad), begitu pula yang terjadi antara musta'jir dan ajir baik terkait dengan pekerjaan yang diterbitkan. Pengusaha yang akan memperkerjakan harus lebih dahulu menjelaskan segala terkait dengan pekerjaan yang akan dilaksanakan, baik waktu, jenis pekerjaan dan upah kerja. Selain menjadi market wage dan value of marginal product of labour sebagai

${ }^{2} \mathrm{CNN}$ Indonesia, 5 Provinsi dengan UMP 2019 Tertinggi dan Terendah, https://www.cnnindonesia.com/ekonomi/20181109210347-535-345387/5-provinsi-dengan-ump2019-tertinggi-dan-terendah, diakses tanggal 28-03-2019, pukul 10:53 WIB.

${ }^{3}$ Murtadho Ridwan, Standar Upah Pekerjaan Menurut Sistem Ekonomi Islam, Jurnal Equilibrium, 1, No. 2, Desember 2013, h. 251. 
pijakan dalam menentukan upah kerja, Islam juga mengariskan bahwa upah yang ditetapkan harus mampu memenuhi kebutuhan pokok meliputi, sandang, pangan, papan, pendidikan serta kesehatan para pekerja dan keluarganya secara layak. ${ }^{4}$

Sistem upah Islam menghendaki agar pekerjaan mendapatkan upah yang layak tanpa melanggar hal pengusaha yang sah, dan sebaliknya pengusaha tidak diperbolehkan berlaku sewenag-wenang menghilangkan bagian hak pekerja yang sah. Islam tidak memberikan batasan tertentu tentang upah kerja dan itu berarti bahwa masalah ini tidak mendi fokus pembahasan, sebab keputusan tentang upah menjadi kesepakatan oleh setiap pihak yang terlibat baik pengusaha dan pekerja dan barangkali negara. Islam menekankan nilai-nilai etis berupa keadilan ( $a d l$ ), kebaikan (ihsan), dan rasa kasih sayang (rahman) dalam semua hubungan kemanusiaan.

\section{Pengupahan Tafsir Kontenporer Al-Mishbah}

Pengupahan sangat penting perananya dalam dunia kerja, karena pengupahan merupakan bentuk reward(penghargaan) ke pada pekerja agar pekerja dapat berkerja dengan semangat dengan hasil yang di capai. Pengupahan yang baik dans esuai juga telah diatur dalam al-Qur'an agar pekerja tidak mengalami kezaliman dan memperoleh upah sesuai dengan gaji pekerjanya. Ayat yang membahas tentang pengupahan yaitu Q.S. atTaubah[09]: 105, yaitu:

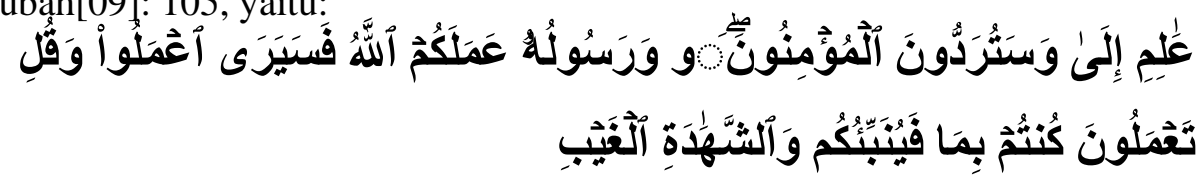

Artinya: "Bekerjalah kamu, maka Allah dan Rasul-Nya serta orang-orang mukmin akan melihat pekerjaanmu itu, dan kamu akan dikembalikan kepada (Allah) Yang Mengetahui akan yang ghaib dan yang nyata, lalu diberitakan-Nya kepada kamu apa yang telah kamu kerjakan. (Q.S. al-Taubah[09]:105) ${ }^{5}$

Katakanlah, wahai Muhammad SAW., bahwa Allah menerima taubat, dan katakanlah juga: "bekerjalah kamu, demi karena Allah semata dengan aneka amal yang saleh dan bermanfaat, baik untuk diri kamu maupun untuk masyarakat umum, maka Allah akan melihat, yakni menilai dan memberi ganjaran amal kamu itu, dan Rasul-Nya orang-orang mukmin. ${ }^{6}$ Ayat lain yang membahas tentang upah juga terdapat di Q.S. at-Thalaq[65]:06, yaitu:

\footnotetext{
${ }^{4}$ Armansyah Waliam, Upah Berkeadilan Ditinjau Dari Perspektif Islam, Jurnal Bisnis dan Manajemen Islam, Bisnis, Vol. 5, No. 2, Desember 2017, h. 273.

${ }^{5}$ Kementrian Agama RI, Al-Qur'an MadinaDilengkapiDenganTerjemahdanMateriTentangAkhlakMulia, Bandung: PT MadinaRaihanMakmur, tt, h. 203.

${ }^{6}$ M Quraish Shihab, Tafsir Al-Mishbah Volume , Jakarta: Lentera Hati, 2002, h. .
} 


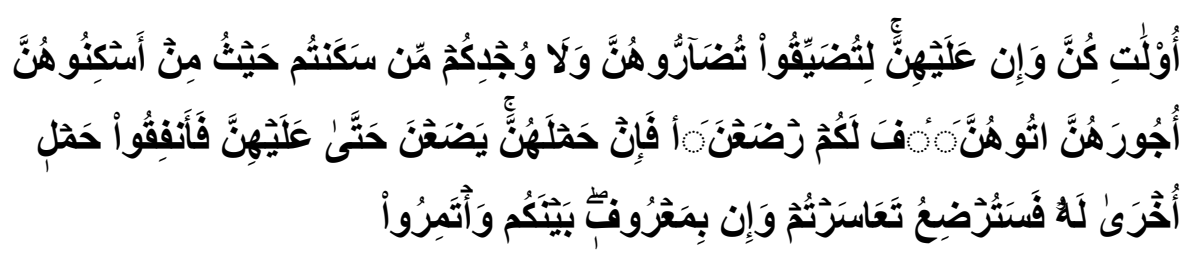

Artinya: “Tempatkanlah mereka (para isteri) di mana kamu bertempat tinggal menurut kemampuanmu dan janganlah kamu menyusahkan mereka untuk menyempitkan (hati) mereka. Dan jika mereka (isteri-isteri yang sudah ditalaq) itu sedang hamil, maka berikanlah kepada mereka nafkahnya hingga mereka bersalin, kemudian jika mereka menyusukan (anak-anak)mu untukmu maka berikanlah kepada mereka upahnya, dan musyawarahkanlah di antara kamu (segala sesuatu) dengan baik; dan jika kamu menemui kesulitan maka perempuan lain boleh menyusukan (anak itu) untuknya.” (Q.S. at-Thalaq[65]:06) ${ }^{7}$

Ayat di atas mempertegas hak wanita-wanita itu memeroleh tempat tinggal yang layak. Ini perlu dalam rangka mewujudkan ma'ruf yang diperintahkan oleh ayat 5 sebelum ini. Ayat di atas menyatakan: Tempatkanlah mereka, para istri yang dicerai itu, di mana kamu, wahai yang menceraikannya, bertempat tinggal. Kalau dahulu kamu mampu tinggal di tempat yang mewah dan sekarang penghasilan kamu menurun atau sebaliknya maka tempatkanlah mereka di tempat sesuai dengan kemampuan kamu sekarang dan janganlah sekali-kali kamu sangat menyusahkan mereka dalam hal tempat tinggal atau selainya dengan tujuan untuk menyempitkan hati dan keadaan mereka sehingga mereka terpaksa keluar atau minta keluar. ${ }^{8}$

Pengupahan dalam Islam yang terdapat dalam AL-Quran tidak hanya ayat di atas, terdapat ayat lain yang membahas tentang pengupahan seperti: QS. Al-Qashas ayat 23-28, QS. An Nahl ayat 9, QS. Al-Jumu'ah ayat 10, QS. An-Nahl ayat 97, QS. Ali Imran ayat 57, dan QS. Al-Kahfi ayat 30. Ayat-ayat tersebut membahas tentang upah yang telah ada dalam al-Qur'an, sehingga bisa menjadi tolak ukur ilmu pengetahuan sebagai landasan baik dalam kaidah maupun dalam bermuamalah. Pengupahan tidak hanya terdapat dalam AlQur'an, sebagai penguat tafsir-tafsir tentang ayat-ayat al-Quran juga terdapat hadist yang menguatkan, seperti hadist berikut:

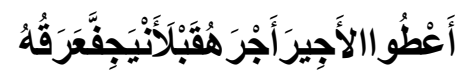

Artinya:

"Berikankepadaseorangpekerjaupahnyasebelumkeringatnyakeri ng.” (HR. IbnuMajah, shahih).

${ }^{7}$ Kementrian Agama RI, Al-Qur'an MadinaDilengkapiDenganTerjemahdanMateriTentangAkhlakMulia..., h. 559.

${ }^{8}$ M. Raish Shihab, Tafsir Al-Mishbah Volume 14, Jakarta: Lentera Hati, 2002, h.142-145. 
Maksud hadits ini adalah bersegera menunaikan hak si pekerja setelah selesainya pekerjaan, begitu juga bisa dimaksud jika telah ada kesepakatan pemberian gaji setiap bulan. Al Munawi berkata, "Diharamkan menunda pemberian gaji padahal mampu menunaikannya tepat waktu. Yang dimaksud memberikan gaji sebelum keringat si pekerja kering adalah ungkapan untuk menunjukkan diperintahkannya memberikan gaji setelah pekerjaan itu selesai ketika si pekerja meminta walau keringatnya tidak kering atau keringatnya telah kering."

\section{Pembahasan}

Banyaknya kasus yang terjadi di masyarakat saat ini dengan upah minumum tidak sesuai dengan yang diharapkan sehingga menyebabkan kurang sejahtra pada masyarakat tertentu. Upah merupakan salah satu alat motivator untuk meningkatkan produktivitas kerja karena upah merupakan imbalan yang akan diterima seseorang setelah bekerja, makin tinggi upah akan membuat karyawan menigkat ptoduktivitas kerjanya. ${ }^{9}$ Upah minimum sudah diatur oleh pemerintah mengenai pengupahan yang melindungi pekerja/buruh pada pasal 88 ayat 1 No. 13/2003 dan dalam rangka meningkatkan daya guna dan hasil guna serta kesejahtraan Pegawai Negeri Sipil, perlu mengubah gaji pokok pegawai negeri sipil sebagaimana diatur dalam Peraturan Pemerintah Nomor 66 Tahun 2005. ${ }^{10}$

Upah yang diperoleh oleh pekerja yang di bawah pemerintahan sudah banyak yang sesuai dengan upah minumum, sedangkan banyak pekerja seperti buruh perusahaan kacil, pekerja guru honorer, upah pekerja UMKM dan banyak lainnya masih tidak sesuai dengan UMR yang di tetapkan oleh pemerintah. Pengupahan dalam Islam mengatur bagaimana upah dapat memenuhi sandang pangan dan papan dari pekerja tersebut. Tetapi pada kenyataanya industri-industri rumahan yang masih kecil perkembangan juga tidak dapat memberikan upah sesuai dengan UMR/UMP karena upah juga ditentukan oleh tingkan pendapatan yang diperoleh dari hasil penjualan.

Menggunakan metode penelitian kualitatif dan dengan pendekatan hermeneutika double movement, Islam mengatur tetang upah agar masyarakat sendiri dapat sejahtra seperti dalam Q.S. at-Taubah ayat 105 tentang bekerja dan memberikan ganjaran seperti apa yang telah di lakukan. Sehingga tafsir tersebut mengarahkan untuk selalu berusaha dalam berkerja karena hasil yang didapatkan nanti tidak jauh dari usaha yang telah dilakukan. Sehingga dalam sistem upah sendiri juga seharusnya menyesuaikan dengan hasil kerja yang dilakukan, jika pekerjaanya maksimal dan dapat mendorong naiknya profit suatu prusahaan maka jelas kewajibanya adalah memberikan upah lebih dari pekerja umum lainya.

${ }^{9}$ Arifatul Chusna, Pengaruh Laju Pertumbuhan Sektor Industi, Investasi, dan Upah Terhadap Penyerapan Tenaga Kerja Sektor Industri di Provinsi Jawa Tengah Tahun 1980-2011, Economics Development Analysis Jurnal, EDAJ 2 (3) (2013), ISSN 2252-6889, h.17.

${ }^{10}$ Peraturan Pemerintah R.I Nomor 9 Tahun 2007 Tentang Perubahan Gaji Pokok PNS (Pegawai Negeri Sipil), Bandung: Citra Umbara, 2007, h. 1. 
Pemberian upah dalam Q.S at-Thalaq ayat 6 tentang menepatkan tempat sesuai dengan kemampuan, maksudnya adalah seperti di dalam indutri kecil yang baru berkembang tidak mungkin dapat memberikan upah yang tinggi karena disesuaikan dengan keuntungan dan tingkat produksi dalam perusahaan tersebut. Sehingga teori tentang upah harus dapat mensejahtrakan keluarganya harus diimbangi dengan bagaimana perusahaan tersebut berkembang.

Anggapan tentang upah harus dapat mensejahtrakan keluarganya itu seperti upah minimum yang di anggap mampu mensejahtakan keluarga pekerjanya. Wujud kesejahtraan bagi pekerja yang dalam perundangundangan dan peraturan-peraturan lainnya salah satunya melalui pengupahan. Upah ini diberikan oleh pengusaha kepada pekerja, dan upah merupakan hak yanh wajib diterima oleh pekerjanya. Namun, tidak semua perusahaan bisa menerapkan dari sisi pemberian upah pada pekerjanya sesuai dengan peraturan. ${ }^{11}$ Sedangkan upah yang berada di bawah standar UMR dianggap tidak mampu mensejahtrakan pekerjanya. Sehingga ketika seseorang meneripah upah yang tidak sesuai atau tidak mampu mensejahtrakan keluarganya, maka hal tersebut masuk dalam golongan ashnap yaitu orang yang berhak menerima zakat.

\section{E. Kesimpulan}

Upah (ujarah) adalah bentuk kompensasi atas jasa yang telah diberikan oleh tenaga kerja. Tafsir kontenporer al-mishbah yaitu tempatkanlah mereka di tempat sesuai dengan kemampuan kamu sekarang dan janganlah sekali-kali kamu sangat menyusahkan mereka dalam hal tempat tinggal atau selainya dengan tujuan untuk menyempitkan hati dan keadaan mereka sehingga mereka terpaksa keluar atau minta keluar. Pengupahan yang sesuai dengan aturan Islam yaitu harus mampu adil, memberikan kelayakan, dapat memenuhi sandang, pangan, dan papan.

\section{F. DaftarPustaka}

Arifatul Chusna, Pengaruh Laju Pertumbuhan Sektor Industi, Investasi, dan Upah Terhadap Penyerapan Tenaga Kerja Sektor Industri di Provinsi Jawa Tengah Tahun 1980-2011, Economics Development Analysis Jurnal, ISSN 2252-6889,EDAJ 2 (3) (2013).

Anggia Permata, dkk, Penerapan Upah Minimum oleh Pegusaha Bisnis Kuliner yang Memiliki Surat Izin Usaha di Kabupaten Jember, eJournal LenteraHukum, Volume 4, Issue 3 (2017), pp . 175-190, h.178.

Armansyah Waliam, Upah Berkeadilan Ditinjau Dari Perspektif Islam, Jurnal Bisnis dan Manajemen Islam, Bisnis, Vol. 5, No. 2, Desember 2017.
Kementrian
Agama
RI,
Al-Qur'an
MadinaDilengkapiDenganTerjemahdanMateriTentangAkhlakMulia, Bandung: PT MadinaRaihanMakmur, tt,.

\footnotetext{
${ }^{11}$ Anggia Permata, dkk, Penerapan Upah Minimum oleh Pegusaha Bisnis Kuliner yang Memiliki Surat Izin Usaha di Kabupaten Jember, e-Journal LenteraHukum, Volume 4, Issue 3 (2017), pp . 175-190, h.178.
} 
Murtadho Ridwan, Standar Upah Pekerjaan Menurut Sistem Ekonomi Islam, Jurnal Equilibrium, 1, No. 2, Desember 2013.

Peraturan Pemerintah R.I Nomor 9 Tahun 2007 Tentang Perubahan Gaji Pokok PNS (Pegawai Negeri Sipil), Bandung: Citra Umbara, 2007.

M. Raish Shihab, Tafsir Al-Mishbah Volume 14, Jakarta: Lentera Hati, 2002.

Siswadi, Pemberian Upah Yang Benar Dalam Islam Upaya Pemerataan Ekonomi Umat dan Keadilan, Jurnal Ummul Qura Vol IV, No. 2, Agustus 2014.

CNN Indonesia, 5 Provinsi dengan UMP 2019 Tertinggi dan Terendah, https://www.cnnindonesia.com/ekonomi/20181109210347-535 345387/5-provinsi-dengan-ump-2019-tertinggi-dan-terendah. 